\title{
Entrevista com o pensador contemporâneo Massimo Canevacci ${ }^{1}$
}

Por: Ana Paula Sabiá 
Massimo Canevacci é um pesquisador singular. Sua formação em antropologia aliada a seu espírito artístico, inventivo e curioso levaram-no a criar e desenvolver pesquisas, métodos e conceitos inovadores e sincréticos sobre as culturas e as relações humanas. Italiano de fala mansa e escrita sedutora, articula com ênfase e paixão suas reflexões ousadas sobre arte, filosofia, pesquisa ou qualquer assunto de seus muitos interesses. Nos anos 80, em ocasião de uma pesquisa de campo no Brasil, apaixonou-se pelo país ao descobrir as múltiplas possibilidades de códigos de linguagens e culturas da sincrética metrópole paulistana e decidiu continuar por aqui. Vê com olhos entusiastas a relação entre os sujeitos e a cultura digital pois, a partir desta, foi possível a interatividade, a participação, o conhecimento e a liberação de discursos e visibilidades que antes eram homogeneizadas ou marginalizadas pela cultura de massa. Convidado regularmente como professor e conferencista em diversas áreas do saber, por inúmeras universidades brasileiras e internacionais, é doutor titular de Antropologia Cultural na Facoltà di Scienze della Comunicazione dell'Università degli Studi di Roma "La Sapienza" (Itália) e, atualmente, integra o Instituto de Estudos Avançados (IEA) da Universidade de São Paulo (USP).

ISSN: $2175-2346$ 
Ana Sabiá: Seu livro SincrétiKa: explorações etnográficas sobre artes contemporâneas (ed. Studio Nobel, 2013) foi um dos mais impactantes que li. A tua maneira de escrita me foi inédita e me pareceu totalmente livre! Seus hibridismos conceituais e re-criações de diálogos entre eles me abriram às novas experiências do pensar a arte e a pesquisa com a arte. O que você considera SincrétiKa, com K?

Massimo Canevacci: Foi uma espécie de imaginação que me ocorreu pois a primeira edição em português do livro", tinha como título "Sincretismos". Porém, aquela edição tinha um problema que não havia sido resolvido e, após mais de dez anos, imaginei que como a pesquisa ainda não estava acabada eu precisava reiniciá-la agora e de uma maneira mais estendida, mais baseada nas pesquisas que eu estivera fazendo nesses últimos dez anos. Assim, imaginei que o titulo também não poderia ser o mesmo e para modificá-lo eu fiz um pequeno jogo pessoal que agora vou revelar, acho que pela primeira vez! Eu publiquei um livro antes em italiano, e posteriormente em português que se chama Culturas EXtremas, e decidi colocar um $\mathbf{X}$ bem grande, que representava um código particular, quase que um símbolo, para desenhar um cruzamento, uma expansão da cultura de um tipo de juventude que não era mais determinada simplesmente por uma questão geracional. Era uma juventude eXterminada, como gosto de dizer, sempre com o X maiúsculo. Então eu gostei de brincar com esse tipo de $X$ grande, com essa letra, e por isso quando pensei em modificar o título, pensei em SincrétiKa com $\mathbf{K}$ maiúsculo. As letras X e K, no idioma italiano, não pertencem ao nosso alfabeto tradicional, quero dizer, apesar de as usarmos normalmente na nossa linguagem. Então, decidi usar um $\mathbf{K}$ maiúsculo para significar uma distorção em relação à primeira edição. Isto é a parte mais pessoal e biográfica, mas também SincrétiKa é também um plural, que não é o mesmo que Sincretismos, com o "s" final do plural em português, mas um plural em parte italiano, latino... digamos, a mistura de línguas que não pertencem exatamente a uma nação específica. Eu inventei o Sincretika (com Ka no final) para pluralizar os conceitos de sincretismos que, de alguma maneira, continua nos dias atuais. A partir desse tipo de mudança na grafia do título, que a editora brasileira Studio Nobel aceitou, mas o editor inglês, que agora está traduzindo o livro, não aceita (pois segundo ele, na Inglaterra o título escrito dessa maneira não funcionaria para o entendimento dos leitores). $O$ inglês apesar de ser uma língua sempre mais global possui algumas regras que dificultam jogar com códigos, letras... Então, aceitei sua sugestão e o livro sairá traduzido² no próximo ano.

AS: É interessante o modo como você coloca o conceito de sincretismo como possibilidades de juntar, cruzar elementos que a principio não pertencem a uma mesma fonte, uma mesma linguagem, para então constituir um terceiro ou um quarto ou um múltiplo que possa ser uma novidade ou algo experimental, e isso é muito buscado pela arte, de maneira geral, principalmente na arte contemporânea. Como se daria essa relação entre essas buscas, esses cruzamentos "impuros" e sincréticos da arte com a questão da subjetividade que, assim como você defende, também é uma multiplicidade nesse momento atual da comunicação digital?

1 Sincretismos: uma exploração das hibridações culturais, Massimo Canevacci, tradutor: Roberta Barni, Editora: Studio Nobel, 1996.

2 Título m Inglês: SYNCRETISMS, Ethnographic Constellation on Cultural Ubiquities. 
MC: Sempre tive uma relação sonora, musical com a palavra sincretismo porque, pessoalmente, é uma palavra que me agrada pela musicalidade, tem uma sonoridade que favorece um tipo de evocação que não é determinada claramente, mas que desloca a percepção e o sentido: sin-cre-tismo, como se a primeira parte SIN criasse uma contradição com a segunda $C R E$, e acabando com uma dimensão mais leve. Para mim, de verdade!, era como cantar notas musicais que informavam à minha sensibilidade...

Quando iniciei a me aprofundar na busca de sentido dessa palavra, busca ainda não resolvida sobre sua origem, enquanto existem muitas filologias histórias sobre isso. Na origem política, era considerada uma forma superficial de imaginar alianças entre grupos rivais em Creta. Depois, com a filosofia que se afirmou no período do Helenismo na Grécia, o sincretismo no Helenismo era considerado uma forma extremamente superficial do pensamento. E enfim, na última dimensão religiosa foi julgado ainda mais superficial, pois era uma antiga vontade de misturar dogmas, princípios e rituais totalmente diferentes criando problemas à doutrina, num sentido mais ortodoxo. Então, essa consideração crítica de superficialidade permaneceu em mim por muito tempo até que, pela primeira vez, em meados dos anos 80 iniciei a viajar pelo Brasil e comecei a me tornar muito interessado pela metrópole que é São Paulo, tanto que a assumi como minha segunda cidade (depois de Roma). Morando em São Paulo e fazendo uma pesquisa sobre a polifonia da comunicação nessa metrópole, comecei a entender que essa polifonia não era de harmonias... de som, de conceitos, de comportamentos e de racionalidades homogêneas, mas que tinha elementos dissonantes totalmente diferente para mim, italiano nascido e criado em Roma, era totalmente diferente. Então, a minha professora foi a Rua Augusta, pois eu morava ali bem pertinho e caminhando pela Augusta eu ficava muito impressionado com a coexistência de códigos totalmente diferenciados que ali estavam, um ao lado do outro. E nenhum código, nenhuma estrutura de um prédio, uma loja, também de comportamento das pessoas, tinha uma unidade identitária definida, como por exemplo se vê em Roma, sabe? Essa coexistência, por exemplo: eu observava em uma esquina da augusta as sete da noite, onde haviam alunos meninos e meninas de 5 a 10 anos e de outro lado, prostitutas. Para mim, essa coexistência de mundos tão diferentes era totalmente estranho! E depois, tinham lojas dedicadas à cultura indígena e outras lojas libanesa, italiana, japonesa, tudo misturado! Essa mistura criava uma polifonia com certeza mas, ao mesmo, tempo era uma polifonia baseada sobre códigos incompatíveis a partir de uma lógica identitária ocidental. Entendi que era uma outra lógica e que não existia - e nem somente era válida - a lógica da racionalidade ocidental, aquela mesma que criticou duramente o sincretismo no período mais bélico da filosofia grega. Então percebi a existência de lógicas diferenciadas... a lógica sincrética era desse tipo, que não tinha como fundamento o princípio de identidade - que é fundamental na lógica clássica - mas uma coexistência do incompatível, códigos que na visão de mundo tradicional de muitas culturas é incompatível. Na Rua Augusta, e em muitos lugares do Brasil, essa lógica sincrética não só era compatível, mas totalmente normal! Então eu via tal coisa, que para mim era estranha, e meus amigos brasileiros me diziam: "Não Massimo, isso é totalmente normal!". Ou ao contrário... 
por exemplo, na avenida Henrique Schaumann, fiquei observando uma lanchonete McDonald's que tinha uma evidente arquitetura de igreja medieval e pensei: "nossa, esse tipo de loja-igreja nunca seria possível construir na Italia e também seria uma blasfêmia fazer um McDonald's replicando uma igreja católica". Lembro que um meu amigo brasileiro muito atento, filósofo também nunca havia refletido esse fato. Para ele era muito normal que o McDonald's pudesse ter esse estilo "igreja medieval". Então eu entendi que o arquiteto dessa lanchonete elaborou essa dimensão de cruzar estilos e códigos diferentes. Não tinha uma pureza identitária única, como uma igreja na Itália ou mesmo o previsível para uma lanchonete, mas misturava elementos... Lembro que a porta de ingresso tinha uma forma redonda que lembrava um hambúrguer e se entrava nessa "igreja" para absorver não a hóstia, mas o hambúrguer... Então, este tipo de deslocamento dos códigos é possível porque existe um entendimento dessa lógica diferenciada que comecei a chamar sincréticas/sincretismo. Continuei verificar estes como alguns dos conceitos importantes na cultura brasileira. Naquele momento estive procurando conceitos importantes também em outras culturas, pois também na Italia que até os anos 80 ainda havia o movimento de emigração, começa a ter um movimento invertido e tornou-se destino da imigração a partir dos 80 e 90 . Então isso começa a afetar e favorecer esse tipo de cruzamento de códigos, comportamento, estilos, palavras, música, comidas que chegou mais tarde do que, por exemplo, na França ou na Inglaterra ... Então, entendi naquele momento, que no Brasil, em São Paulo, era uma metrópole que estava experimentando uma espécie de vanguarda, e que poderia representar essa possibilidade sincrética e afetar comportamentos também em outros países e, claro, na Itália também. Hoje vejo que o processo de misturar culturas, pessoas, símbolos, religiões é uma coisa complicada, não é assim tão simples como pensava naquela época. Obviamente, agora vejo elementos conflituais muito fortes, mas nos anos 90 e começo do século XXI eu estava convencido a essa tendência liberatória, no mundo global e local, de culturas cada vez mais sincréticas, cruzadas.... Hoje sou mais cauteloso, pois vejo acontecer em muito lugares, não tanto no Brasil, mas na Europa questões relacionadas ao conflito de culturas, como por exemplo o caso do burquini, do fundamentalismo religioso ou do racismo declarado. A coexistência de códigos estrangeiros as vezes podem criar um tipo de 'belo' sincretismo mas, também, podem criar um fechamento etnocêntrico e tentar reafirmar essa lógica binária e identitária que eu continuo a criticar. Este é um exemplo clássico, de cidades como Nice onde agora é proibido usar burquini e, sempre mais, na Alemanha onde a chanceler Angela Merkel esta projetando uma lei para determinar em quais circunstâncias será aceitável usar burquini ou mesmo a burca. Assim, a minha ideia progressista e otimista, atualmente apresenta-se mais cuidadosa, nessa dimensão política. Com a arte é diferente, a arte não acompanha a política e os senso comum das pessoas. A arte tem esse tipo de capacidade de deslocar e maravilhar, de apresentar expressões estéticas que não são aceitas da sensibilidade comum. Acho que as artes (pluralizando suas expressões) tem um papel fundamental nesse ponto pois tem uma capacidade não de acompanhar a tradição comum, mas antecipar e às vezes deslocar o que é considerado normal. Os grandes artistas demonstram que nada pode ser fixo no campo da arte, nem da política e nem da moral. Nesse sentido, as artes tem a capacidade "antecipadora". Então eu fiquei in- 
teressado nesse sentido antecipador das artes contemporâneas e tentei escolher os artistas mais diferenciados, seja no campo da arte pictórica, do cinema, da literatura, da moda... que pudessem representar um cenário aberto em direção a esse tipo de projeto que eu tenho em afirmar a potencialidade libertadora dos sincretismos.

AS: A etnografia é uma prática de pesquisa que, vinda da antropologia, agora encontra-se também como processo metodológico em outras áreas, principalmente às das ciências humanas. A voz do Outro não é mais representada pelo pesquisador, mas cada um hoje tem ou cria ferramentas de auto-representação. Como se dá esse trânsito de etnografia na arte e vice-versa?

MC: Muito bom. Já no inicio do século passado Malinowski afirmou que o método da antropologia moderna era fazer a pesquisa no campo, o que ele chamou de etnografia. A etnografia é uma pesquisa com uma descrição muito minuciosa e atenta aos mínimos particulares de uma cultura diferente daquela do pesquisador antropólogo. Por isso ele determinou a metodologia da pesquisa no campo que foi, e penso ainda é, fundamental. Malinowski escreveu, exatamente, que a observação participante era um tipo de metodologia que permitia inserir na pesquisa não somente os outros, mas também o pesquisador. Por isso, se Malinowski queria analisar um ritual, participava também ele do ritual. Ele participava e ao mesmo tempo aprendia a "se olhar" participando. Isso é mais ou menos a origem da etnografia como parte da antropologia cultural e virou um método utilizado por muitos e muitos anos até, mais ou menos, o final do século passado onde começaram se afirmar os estudos culturais na Grã-Bretanha, Inglaterra. Os estudos culturais buscavam entender os comportamentos da juventude de então, ou as novas gerações, utilizando a metodologia da etnografia. Então a etnografia, que era um método de olhar outras culturas, tornou-se também um método de análise da própria cultura, da juventude, dos marginalizados, etc... Então essa transformação da etnografia expandiu-se em estudos culturais cada vez mais importantes e, posso dizer que, a etnografia atualmente não é relacionada a uma disciplina, que é a antropologia cultural. Aliás, eu posso dizer que a etnografia é indisciplinada, ela ultrapassa a rigidez das disciplinas como ainda são colocadas dentro das universidades em departamentos, linhas de pesquisa, referências bibliográficas... A grade curricular dos alunos, desde a graduação até doutorado, ainda é fechada, determinada à instancia de um saber circunscrito a certos assuntos e isso é realmente uma coisa do século passado! $\mathrm{Na}$ atualidade, acho que o pesquisador junto com seu orientador, tem a possibilidade de criar e vincular uma pesquisa que aborde, por exemplo, a física quântica, um índio xavante do Mato Grosso e Picasso! Eu acho que as universidades on line que, não casualmente, vêm se afirmando, por exemplo na California (Stanford, Berkeley, mas a Harvard também), é pelo fato de não serem baseadas em currículo e nem sobre um departamento. Por isso a etnografia é uma ponte para afirmar uma metodologia indisciplinada que tem uma característica fundamental: a pesquisa no campo. Porque a pesquisa no campo é a beleza da universidade. A universidade somente funciona se professores, pesquisadores e alunos aceitam e gozam e desejam fazer pesquisa no campo, pois a universidade não pode reproduzir o saber tradicional, precisa criar sempre novas sabedorias, que 
por sua vez são criadas estando em campo, dialogando com a vida em movimentos diversificados. A etnografia é exatamente isso, cada pesquisador deve elaborar seu método - não de acordo com um procedimento "geral", clássico, que hoje tende a não funcionar - pois compreende-se esta como uma prática descentrada, multiplicada dentro do panorama vivo do pesquisar. É uma prática que dialoga com a literatura, com a poesia, com a ciência, com a criação do desconhecido.

AS: Muitos professores, teoricamente, orientam seus alunos nessa direção da criação da pesquisa, na inovação do argumento, na atualização epistemológica e/ou formal. Porém, no momento de defesa ou escrita de tese voltam atrás e reafirmam os engessados padrões acadêmicos para "garantir" a cientificidade. No caso da conflituosa relação artes visuais e academia, a produção plástica está sempre a mercê da legitimação escrita no sistema binário que "pontua" e padroniza a competência acadêmica. Acho interessante destacar que você trata dessa relação visual das artes e da pesquisa, no âmbito acadêmico, a partir do teu conceito "óptica-eróptica". Fale um pouco sobre essa relação, sobre o erotismo e o fetichismo, sobre o olhar, ser olhado e se perceber olhando.

MC: Ah que coincidência! Essa semana mesmo me convidaram para uma palestra em uma universidade do $A B C$ em São Paulo para discorrer sobre esse assunto, falar sobre a eróptica. Eu sempre fui interessado, diria apaixonado, pela dimensão do olho, do olhar e do visual. Até minha adolescência eu fui muito fechado, recluso em mim mesmo e a minha expansão deu-se, particularmente, de um refinamento inconsciente de olhar meu cotidiano em Roma. Mais tarde, quando estudei e me tornei professor, busquei desenvolver esse tipo de paixão pelo olhar, que tem elementos que, acredito, não ter nada de natural: aprende-se a olhar. É um treino olhar, sempre disse aos meus alunos, que é preciso desenvolver a própria percepção a respeito do que estamos vendo. Acontece assim na pesquisa, na publicidade, ainda mais na arte, pois na sutileza de olhar é preciso estar atento a cada detalhe, cada mínimo particular é importantíssimo! Um dos livros mais apaixonantes, aliás, pessoalmente é o livro mais erótico que foi escrito sobre o assunto é "La storia dell'occhio" (Histoire de l'œil) de George Battaille. Battaille é um autor muito importante, não apenas porque foi um dos participantes do surrealismo na França daquele período, mas ele também fundou um tipo de academia transdisciplinar com a sociologia, onde se enfrentavam questões totalmente diferentes daquelas circunscritas à academia tradicional. Ele estava imerso também na antropologia, estudou o ritual, o sacrifício e também sobre a erótica - que, até então, não era vista pela antropologia como campo de pesquisa com ele isso se deu. Mais tarde, vim a descobrir que esse seu livro havia sido ilustrado por um outro grande artista dadaísta, Hans Bellmer. Bellmer tinha uma capacidade, totalmente irregular, em representar uma erótica absolutamente fora da normalidade, de qualquer normalidade. Eram corpos diferenciados, múltiplos, segmentados, parcializados, olhos que penetram em qualquer lugar no corpo humano... Tudo isso criou para mim uma tensão muito forte sobre a potencialidade de entender o que significa uma erótica que não seja a reprodução banal de elementos tradicionais. $\mathrm{E}$, por isso, na universidade eu busquei, com um grupo de alunos e alunas, elaborar um 
seminário que nomeei "Eróptica", que para mim era justamente esse cruzamento, um sincretismo entre a óptica e a erótica. A óptica, para mim, é o olhar como força, como capacidade de penetrar nos lugares mais secretos. Olhos é a fonte da erótica. Por isso eu dizia que o olho e o olhar não é determinado naturalmente pela biologia. Apesar de existir aí um lado biológico, a maneira de olhar e apreender muda com o tempo e essa transformação envolve também a dimensão erótica. Um exemplo é que as primeiras pinturas eróticas feitas em Pompeia, Itália, e depois no renascimento e depois com pintores que tentaram representar La Philosophie Dans Le Boudoir, do Marques de Sade, é um tipo de desenho que tinha um erotismo sempre igual, o rosto e o olho era expressão. Não havia uma capacidade de expressão tanto fisionômica quanto erótica. Eu me questionei sobre esse assunto e depois elaborei minha hipótese de que a capacidade de um pintor representar a dimensão orgástica na expressão do rosto foi caracterizada com o advento da fotografia. A fotografia alcançou imediatamente a dimensão erótica, levou diretamente ao público esse lado sexual do orgasmo. Aqueles que trabalharam com a fotografia sexual no final do século XIX são totalmente interessantes por diversos motivos. Naquele momento já se percebe que, com a fotografia, havia a capacidade de encontrar um modo de olhar um rosto, uma expressão, que não era mais uniforme, mas sim deformada. Essa deformação produziu nos olhos, no olhar, novos códigos determinantes que afirmaram outra eróptica. E, obviamente, na transição da fotografia para o cinema e, daí para a cultura digital, tudo isso se ampliou ainda mais. A questão da investigação, que enfatizo, é afirmar a dimensão do desejo, do envolvimento emocional, da personalidade inteira do etnógrafo que não é apartada no processo da pesquisa mas, sim, envolvida.

Cito novamente como exemplo Malinowski, que escreveu sua pesquisa baseada sobre a moral daquele período. No entanto, em seu diário secreto, achado somente após de sua morte, havia escritos sobre o lado sexual, erótico, instintivo e mesmo colonizador ou sexista que o pesquisador não contara na pesquisa "oficial". Por mais que (dados como estes) não conste em sua pesquisa é evidente que ele se envolvera não apenas sensivelmente como também sexualmente. Há sempre um envolvimento cultural, carnal, físico, sexual e erótico que envolve a pesquisa. Então, porque censurar tudo isso? Por que censurar o envolvimento corpóreo, erótico dentro da metodologia da pesquisa? Isso pode ser desenvolvido de maneira mais complexa na narrativa, tanto da narrativa que acontece 'fora' quanto daquela que acontece 'dentro' do corpo do etnógrafo, a fim de se potencializarem para algo inesperado.

AS: Quando você se percebeu 'desejando' a arte contemporânea, interesse que te levou a aprofundar muitas de suas pesquisas nesse assunto e como se dá essa tua afecção, a partir do modo que você afirma que quando nos permitimos penetrar a arte e, também, deixar-nos ser penetrado por ela jamais seremos idênticos ao que antes fomos, já que a transformação nos é possível através da arte?

MC: Então, isso vem de uma questão pessoal, biográfica. Meu pai era pintor e eu sempre fui interessado em pintura. Com minha mãe, comecei a me apaixonar pelo cinema, mas não aquele tipo de cinema mais popular, mas aquele tipo de filme que tinha uma capacidade de ultrapassar o senso comum. Essa minha predileção, mais tar- 
de, tornou-se um problema, pois na minha formação 'acadêmica' eu tive que estudar a musica popular, os rituais religiosos como a procissão na igreja, tive que que estudar todas as atividades ditas folclóricas. Mas, o fato é que nunca me interessei pelo folclore, o que gerou um problema, pois estando na Italia, o que se tinha e gerava grandes estudos eram aqueles com a tradição popular. Então nos anos 80 e 90, apesar de haver feito algumas pesquisas no folk, na cultura popular italiana, iniciei aquela que era minha paixão na vanguarda, na experimentação. Eu sempre adorei os movimentos artísticos de vanguarda, os ismos: o futurismo, o dadaísmo, aquela vanguarda da primeira metade do século XX. Para mim ainda são extraordinários, consigo ainda admirar meu pintor preferido daquele período e ver uma beleza incrível, porque é uma transformação radical da percepção também das dores. Como estávamos dizendo, os futuristas tinham Bocconi como ícone. Milão deixava de ser uma cidade para tornar-se metrópole e o conceito de simultaneidade é algo que aparece nos cubistas e futuristas, com a ruptura de linearidade da percepção, também na literatura, na música. O surrealismo criava uma relação com o inconsciente. O movimento dadaísta também era totalmente irregular, então as três grandes vanguardas artísticas na Europa estavam ultrapassando um tipo de moral, também sexual e política. O futurismo era articulado em uma dimensão mais nacionalista, que virou fascista, e outra mais anárquica, que virou comunista. Os surrealistas eram todos de esquerda, aliás, ainda mais irregular pois recusavam qualquer forma de organização política. Tudo isso era, para mim, extraordinário, a transformação das artes visuais clássicas... O cinema, daquele período dos anos 20 e 30 do século XX era, ainda é para mim, super fascinante, maravilhoso...! E tem a música, onde no ano de 1967 minha vida mudou depois de escutar John Coltrane. Casualmente encontrei em Coltrane, e em particular no seu disco África, e entendi que a maneira dele afirmar musicalmente a cultura afro-americana dos EUA e a África era baseada em uma capacidade incrível de criar uma estrutura musical, sincrética para mim, e viajar com uma capacidade de espontaneidade e criatividade que não tinha limites na dimensão visionária da música. Por isso, ouvir música foi, e ainda é, fundamental para minha experiência subjetiva. Sempre gostei de um tipo de música clássica, Beethoven, Puccini, mas ao mesmo tempo tem um tipo de música que é fundamental, que é aquele tipo que antecipa uma sensibilidade sônica em relação ao tempo em que se está vivendo. Foi assim com Coltrane, assim como com Beethoven, com Bob Dylan e Elvis Prestley, eu nasci também com o Elvis (rs)... isso para mim foi uma revolução íntima na minha percepção de querer corpomúsica e que é a antropologia. Para mim, a antropologia era muito mais baseada em Elvis Prestley, Bob Dylan e Coltrane do que sobre o canto popular na Sardenha, que é certamente belíssimo, mas que para mim não era tão importante... O caso é que não posso somente estudar o canto popular da Sardenha, para mim a coisa importante é conectar o canto popular sardo com John Coltrane. Assim, por exemplo, faz Paolo Fresu que tem essa capacidade de misturar elementos da cultura dele, da Sardenha, com outros elementos que pertencem ao mundo inteiro. Eu gosto disso, essa é a minha antropologia que não fica parada na tradição, mas cria ponte entre tradição e inovações. Por isso, os meus autores mais queridos, mais apaixonantes são sempre aqueles que tem a capacidade de te fazer desconectar de uma identidade. $\mathrm{Na}$ arte, por exemplo, para mim é importante... olha, não quero definir a arte, mas ela tem um 
poder. O pode da arte para mim é o estupor ...

Você tem uma identidade, um sistema perceptivo, de valores, de moral e público que funciona em determinado contexto histórico, cultural e subjetivo. Então, você se depara frente a frente com Guernica, de Picasso, ou então com os auto-retratos de Cindy Sherman, e entende que o sistema perceptivo que você tinha não é mais adequado para entender a deformação de Guernica ou esses códigos, aparentemente normais, mas que são totalmente construídos, estereotipados como nos retratos de Cindy Sherman! Então, você se defronta com esse tipo de obras que destróem a sua identidade, não só a sua normalidade. A arte não é reproduzir a normalidade, uma arte normalizada é morta! Uma arte museificada é destruída! Então, a única arte que, para mim, é aceitável é aquela que causa um profundo mal estar no meu sentimento, na minha percepção, nos meus valores normalizados e me leva em uma direção desconhecida. Esse lado desconhecido entrevisto com uma ópera musical, artística, literária, fotográfica, afirma o máximo valor da minha existência baseada sobre o espanto, o estranho, o estupor. Isto é, a minha existência, ao menos na minha capacidade antropológica, é determinada pela habilidade de encontrar e descobrir artistas que criam uma deformação da minha identidade e me favorecem entrar em crise comigo mesmo para que eu possa transformar-me em outra direção. Por isso, arte e antropologia são assim intimamente interconectadas, que somente esse tipo de experiência, de vivência, de sentimento me são válidos... A última coisa, é o meta-fetichismo, que em minha pesquisa se dá sobre uma antropologia não antropocêntrica, no sentido que o antropos não é mais o centro da minha investigação, mas é uma antropologia onde eu insiro coisas, objetos, mercadorias e também animais, minerais e vegetais. Essa intenção cria uma multiplicidade de existências e de seres que, em particularmente esse fetichismo, tenta se liberar de sua leitura colonial, de matriz portuguesa às voltas do ano 1500, depois retificada e pervertida com Marx e Freud depois, agora com o senso comum que tem um valor de impureza moral. Para mim, o meta-fetichismo significa que o fetichismo tem uma potencialidade que vai além do dualismo sujeito-objeto. Essa potencialidade de colocar em crise o pensamento dicotômico e binário - que, infelizmente, sempre foi discriminado como algo regressivo de um Homem selvagem ou sem cultura, e era o modo de como o fetichismo era percebido na dimensão portuguesa - deveria ser explorada. Acredito que a aliança entre metafetichismo e metamorfose poderia desenvolver uma libertação de coisas e seres que teriam, digamos, o mesmo direito de existência de uma pessoa. Trato disso no meu livro "Fetichismos Visuais".

AS: Algo intrigante é que você traz o Benjamim, com o conceito aurático da obra de arte e a reprodutibilidade técnica não como consequências de desencontro ou fragilidades, mas sincretizando as potencialidades entre um e outro. De que maneira isso pode ser atualizado no contemporâneo a partir da comunicação virtual?

MC: Eu acabei de escrever um ensaio sobre isso, saiu ainda somente em inglês entitulado Digital Auratic Reprodutibility, que é mais ou menos isso... acho essa análise de Benjamim extraordinária, fundamental sobre a obra de arte. Só que ela é histo- 
ricamente determinada, pois a dialética entre aura e reprodutibilidade é uma dialética que funcionava somente naquele período. Enquanto, em parte, Adorno já a criticava, Benjamim afirmava que a dimensão reprodutível do cinema tinha uma potencialidade anti-burguesa e anti-aristocrata que congregava essa visão popular, operária, proletária da arte, e por isso revolucionária. Acho que esse outro lado não funcionou, isto é, a arte reprodutível não tornou-se revolucionária, mas aconteceu algo que foi muito interessante. A era da comunicação digital favorece o cruzamento, e de novo um sincretismo incompatível, entre a aura e a reprodutibilidade. Essa reprodutibilidade aurática é característica da cultura digital, com social network que se pode colocar um texto, video, imagem... E a imagem agora "viaja" na rede, isso é, eu não sou mais o dono de um certo tipo de conceito-imagem, mas qualquer pessoa intervém com outro tipo de sentido, modificar o que estou dizendo, se apropriar... a imagem irá à lugares inimagináveis! Então, a cultura digital tem a potencialidade de misturar a experiência aurática "hic et nunc" como, em parte, estamos fazendo agora e, ao mesmo tempo, afirmar a dimensão reprodutível, justamente como estamos fazendo ${ }^{3}$ agora! Por exemplo, você poderia transformar essa nossa entrevista em coisas que eu não tenho controle, poderia virar uma entrevista para um jornal, poderia virar uma montagem sônica, uma música contemporânea... há uma multidão de expressões porque isso é favorecido pela cultura digital em sua auratic virtual reprodutibilily.

\section{AS: Massimo, então, para finalizar o que você poderia trazer como sugestão de artistas, descobertos em suas pesquisas recentes, que traduzem os conceitos e assuntos que discutimos aqui?}

MC: Adoro Nele Azevedo, uma artista mineira que vive em São Paulo e que, infelizmente, é mais conhecida no exterior do que aqui. Ela tem um trabalho feito de gelo que são inúmeras pequenas estatuetas em formato de pessoas. Ela instala essa obra em espaço aberto, em praças e que, então, inicia o processo natural de descongelamento que torna-se extremamente emocionante, dramático... em acompanhar essa figurinha em um processo que a torna cada vez mais frágil, cada vez menor até finalmente desaparecer em uma poça d'água. É como viver, de alguma maneira, a experiência de cada um, pois nosso corpo também é feito de água, e da mesma forma também desapareceremos um dia... Essa obra da Nele Azevedo me emociona sempre e acho que ela deveria, cada vez mais, ser reconhecida. Outro artista é Jimmie Durham, de origem cherokee e que atualmente vive em Nápoles, que ironiza a representação estereotipada de sua cultura, a "cultura selvagem". Esse tipo de deslocamento que ele faz da cultura indígena dele é incrível, por exemplo, tem uma obra dele que adoro. Ele fotografou seu pai e mãe vestidos com roupas ocidentais... nada do que as pessoas ainda esperam de indígenas com a idéia de adornos de penas, rosto pintado e fazendo uga-uga. Não é assim! A cultura se desloca, se estranha e sincretiza em sua identidade e sua arte. Desse modo, ele transita da sua cultura indígena até Nápoles, criando um sentimento e uma tensão de culturas diferentes que podem e se misturam graças aos artistas contemporâneos. Precisamos de cherokees em Nápoles e, talvez, até em São Paulo...

3 entrevista acontecida via Skype em setembro de 2016. 